\title{
OPTIMIZATIONOF FUSELAGE SHAPE FOR BETTER PRESSURIZATION AND DRAG REDUCTION
}

\author{
Manish Kumar ${ }^{1}$, Geetesh Waghela ${ }^{2}$, Nakash Nazeer ${ }^{3}$ \\ ${ }^{1}$ School of Aeronautical Engineering, Hindustan University, Chennai, Tamilnadu, India \\ ${ }^{2}$ School of Aeronautical Engineering, Hindustan University, Chennai, Tamilnadu, India \\ ${ }^{3}$ School of Aeronautical Engineering, Hindustan University, Chennai, Tamilnadu, India
}

\begin{abstract}
The fuselage of any aircraft is essentially to accommodate the payload. It is normally not as streamlined as the wing. Cabin pressurization has been a major concern in the manufacturing of aircrafts. Generally, a cylindrical shape is preferred from a pressurization point of view as it has a higher strength and weighs less too. On the other hand, a sphere is considered as the best pressure vessel among all the shapes, but, sphere being a bluff body is not suitable for carrying payloads. On this note, a cylinder is considered to be better than a sphere to carry the payload and mainly to achieve a streamlined flow. In this paper, the shape chosen is a combination of the sphere and the cylinder to achieve optimum results for pressurization as well as a better streamlined flow. Our prime aim is to convert this bluff body into something more efficient and useful, rather than only for carrying the payload. We have focused basically on two details viz. 1) Better Pressurization and 2) to assist in minimizing the drag, thereby increasing the overall lift of the aircraft and hence increasing the fuel efficiency. The proposed fuselage structure was designed in CATIA V5 software and structural analyses were done in Auto-Desk Multi-Physics software. As a result, a better structural load capacity was found. A load of $10 \mathrm{~N} / \mathrm{mm} 2$ was applied on both the bodies under consideration (cylinder and ellipse) having the same material, surface area, volume and weight. For the proposed elliptical design, $78 \%$ reduction in the minimum stress value and $10 \%$ reduction in the maximum stress value were noticed.
\end{abstract}

Keywords: Fuselage, Lifting Fuselage, Drag Reduction, Pressurization, Hoop Stress, Multi body design, Toroidal Shells, Multi-cylinder, Channel Propeller Configuration, Carbon Fiber, Graphite Fiber, Stabilization and Carbonization.

\section{INTRODUCTION}

The fuselage is the center body section to which other aircraft components are joined. Especially in flight, the fuselage experiences high bending moments and torsional loads which it has to withstand. These forces are usually due to the rudder movement. Therefore, the fuselage should be structurally sound while maintaining a low weight.

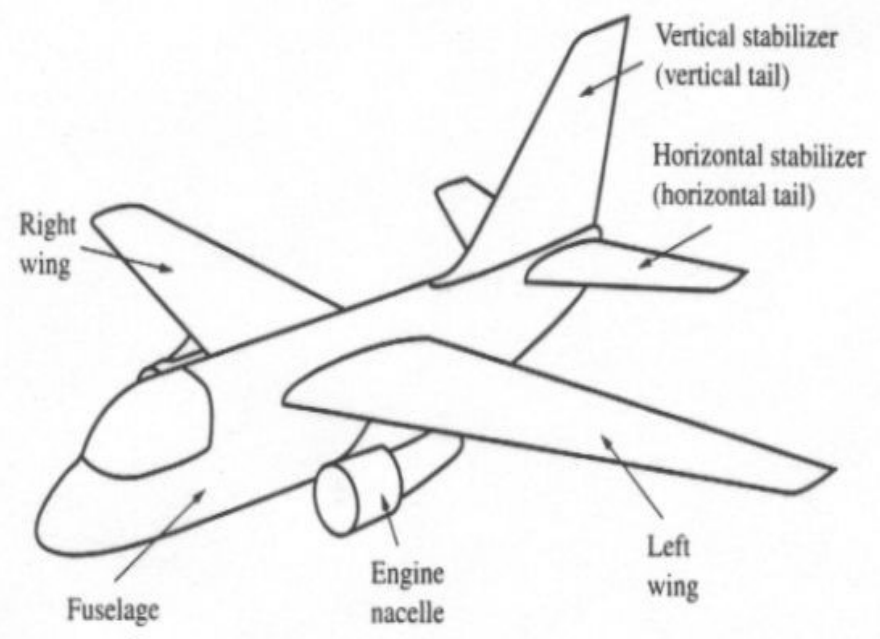

Fig 1: Aircraft Parts
Transport and civil aircrafts have a similar fuselage structure. Overall, the fuselage can be considered as a cylindrical section with either ends tapered. These end sections constitute the nose and tail of the aircraft

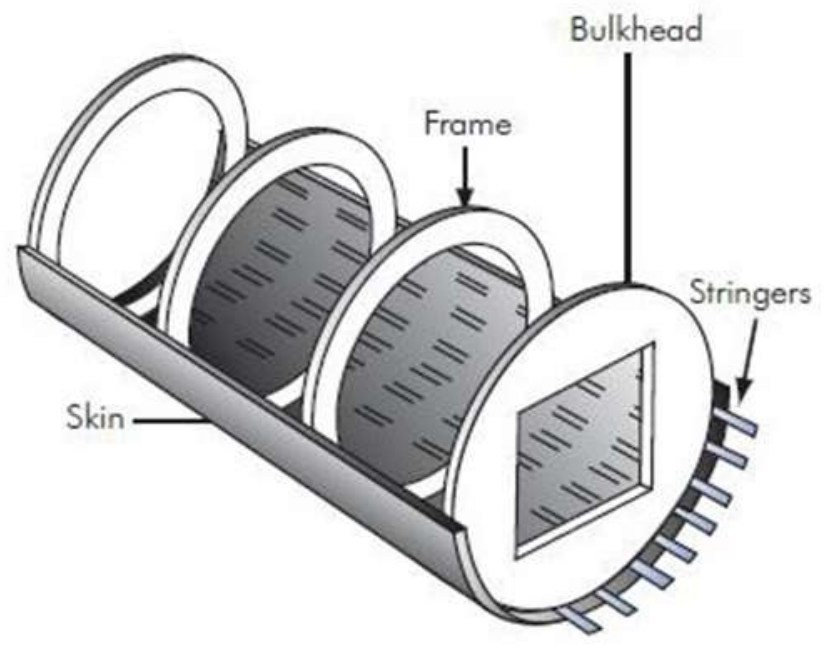

Fig 2: Parts of Fuselage

The general design used in the present day aircraft consists of a semi-monocoque structure. This type of construction 
has been considered due its stability and light weight. It consists of a skin that takes up all the loads supported with stringers for stability enhancement. Perpendicular support members are also present which keep the fuselage in shape when flight loads are acting on the fuselage. These perpendicular supports are called frames or bulkheads depending on whether they are open or closed, respectively. A uniform cylindrical structure is structurally sound, but as the requirements of discontinuities like doors and windows present themselves the structure of the fuselage is compromised. The area around these cutouts must be reinforced or else the cylinder wouldn't be strong enough. The fuselage is hollow in order to reduce weight and accommodate more payloads. The shape of an aircraft's fuselage is dependent on the purpose of the aircraft. This holds true for other parts too. For example, in order to experience less drag, a fighter jet uses a streamlined and slender fuselage for its missions. On the other hand, a transport or civil aircraft doesn't have to focus on speed and hence has a wide body fuselage. These type of aircrafts have to carry heavy payloads that constitute mostly of cargo and passengers. The forward tapered section of the fuselage is called the nose where the cockpit is located. The rear end is referred to as the tail used to carry payloads. The fuel for the mission is typically stored in compartments present in the wing sections.

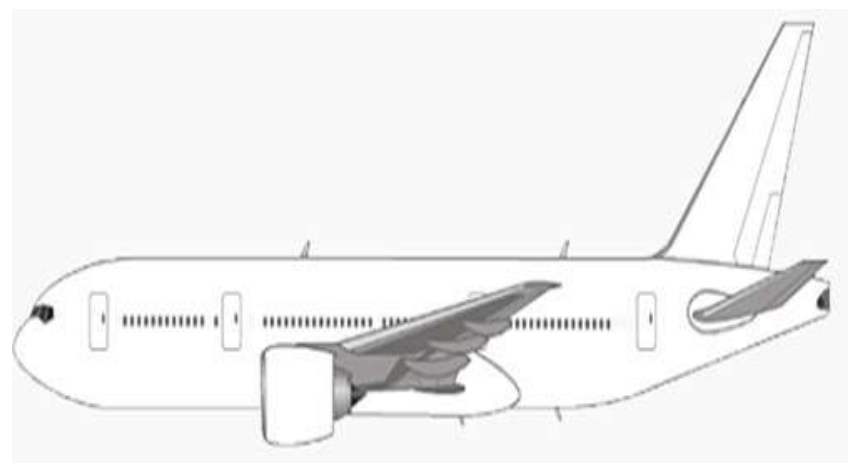

Fig 3: Cross sectional View

The configuration is different in case of a fighter jet. The pilot is seated in a small compartment present on top of the fuselage. The engines are usually at the tail section where the fuel is also stored. The wings carry weapons and ammunition.

The aircraft weight distributed all along the body of an aircraft. Weight plays a major role in flights. The cargo and passengers are the main load constituting members in a civil aircraft. This load has to be monitored before every flight. In flight, the aircraft rotates around the center of gravity. The rotation is primarily caused due to the movement of control surfaces which induces torque. Therefore those designing a fuselage such factors should be noted so that the structure is capable of withstanding such dynamic forces. Pressurization of the fuselage has been a major concern in aircraft manufacturing. A cylindrical shape is generally preferred from pressurization point of view and this shape has high strength and low weight when compared to other shapes. Spheres are not preferred even though they are considered to be the best pressure vessels. The issue lies in spheres being bluff bodies and impractical in accommodating passengers and payload. Cylinder is considered to be better than sphere to carry the payload and to achieve streamlined flow.

In this paper, the shape chosen is a combination of the sphere and the cylinder (i.e. Multi-bubble Design and Oval Shape) to achieve optimum results for pressurization and a better streamlined flow over the flow also structural analysis has been done using Autodesk Multi-Physics software.

\subsection{Multi Bubble Design}

What is MBD?

In structure point of view it is an efficient fuselage design with respect to balancing the pressurization loads. It is a systematic arrangement of cylinders which provide good pressurization. The outer contour of the MBD is an ellipse, a shape that helps in providing a better streamlined flow.

Few details about the MBD are discussed below:

Three different membrane elements are composed in multibubble design:

1) The cylinder which is a constituent of multi-cylinder.

2) The sections that close the multi-bubble, called multisphere and

3) The toroidal shells that are connected into a multi-torus.
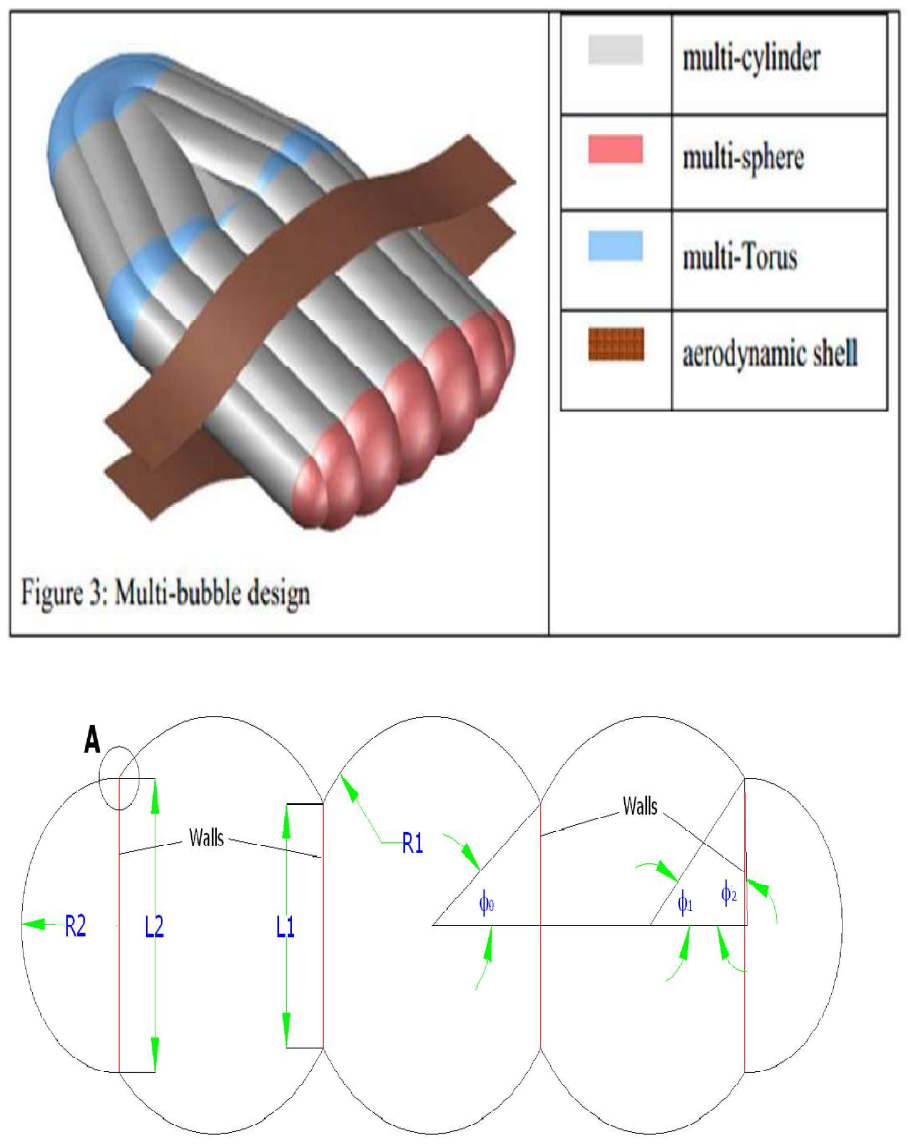

Fig 4: MBD Design 
The cylinders are dimensionally arranged in such a way that the horizontal component of the membrane load of one cylinder is balanced by the horizontal component of the membrane load of the neighboring cylinder. In addition, with different diameters can be connected to control the geometry of the frontal area and bubbles of fuselage.

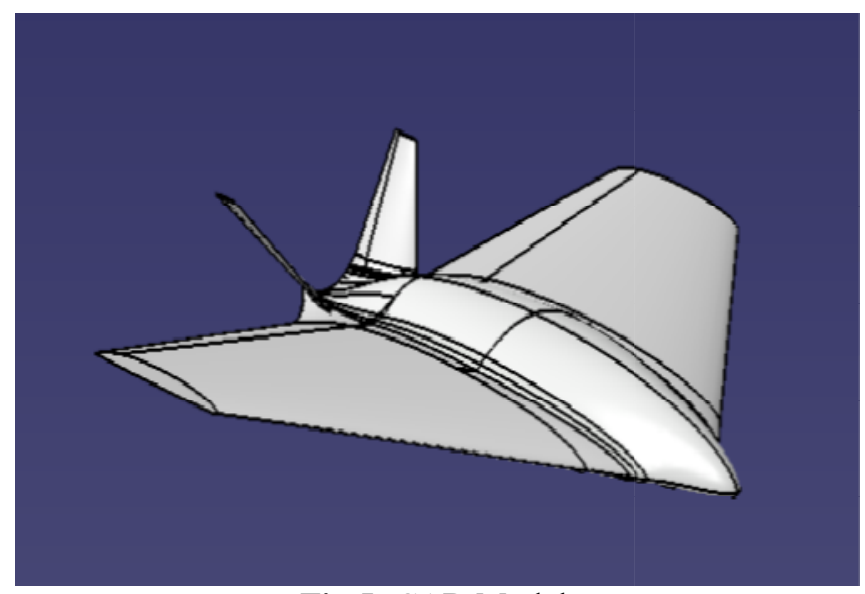

Fig 5: CAD Model

\section{ANALYTICALANALYSIS}

OF

THE

\section{FUSELAGE SHAPES}

According to Laplace's law "larger the wall tension required to withstand a given internal fluid pressure for given larger the vessel radius". Hence, A spherical vessel will have half the wall tension of a cylindrical vessel for a given vessel radius and internal pressure.

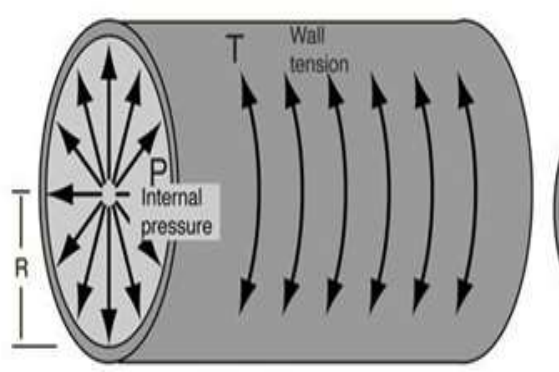

Cylindrical Vessel $T=P R$

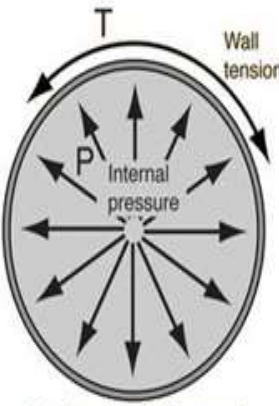

Spherical Vessel $T=\frac{P R}{2}$
Fig 6: Tension for cylindrical vessel

If the upward part of the fluid pressure remains the same, then the wall tension must remain the same at the downward component. But for the less curvature the total tension must be greater in order to get that same downward component of tension. For a load hanging on cable be in equilibrium, we can explore the effects of having a smaller angle for the supporting cable tension.

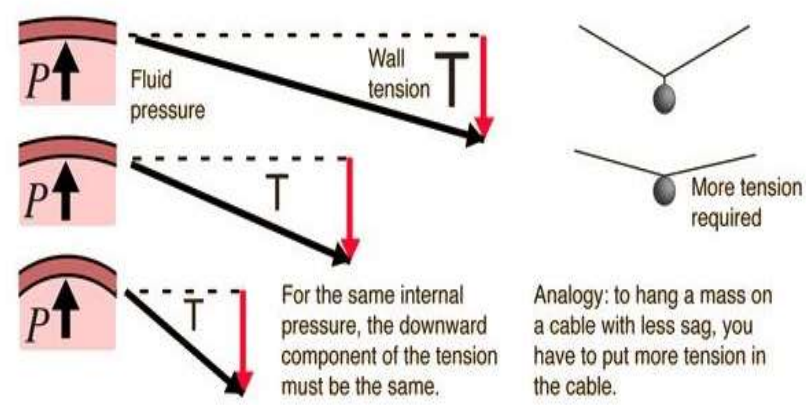

Fig 7: Cable Tension Illustration

In the aircraft, pressurization has been a cause for concern. The load acting on the fuselage is hoop stress. This stress can be roughly calculated using the equation for hoop stress in an infinitely long cylinder subjected to an internal pressure load.

Stress $=$ P.r $/ \mathrm{t}$

$\mathrm{P}=$ Internal Pressure

$\mathrm{r}=$ cylinder radius

$\mathrm{t}=$ cylinder wall thickness

For our model, the calculations are as follows

$\mathrm{P}=10 \mathrm{~N} / \mathrm{mm} 2 \mathrm{R}=300 \mathrm{~mm} \mathrm{~T}=10 \mathrm{~mm}$.

Hoops stress $=300 \mathrm{~N} / \mathrm{mm} 2$

Stress analysis carried out on a cylindrical fuselage is shown in fig9. The stress analysis is selected because it is a best way to denote the pressure distribution on the surface.

Minimum stress value $=123.08 \mathrm{~N} / \mathrm{mm} 2$

Maximum stress value $=306.25 \mathrm{~N} / \mathrm{mm} 2$

\subsection{Structural Analysis of the Fuselage Shapes}

The shape chosen is a combination of the sphere and the cylinder to achieve optimum results for pressurization and a better streamlined flow.

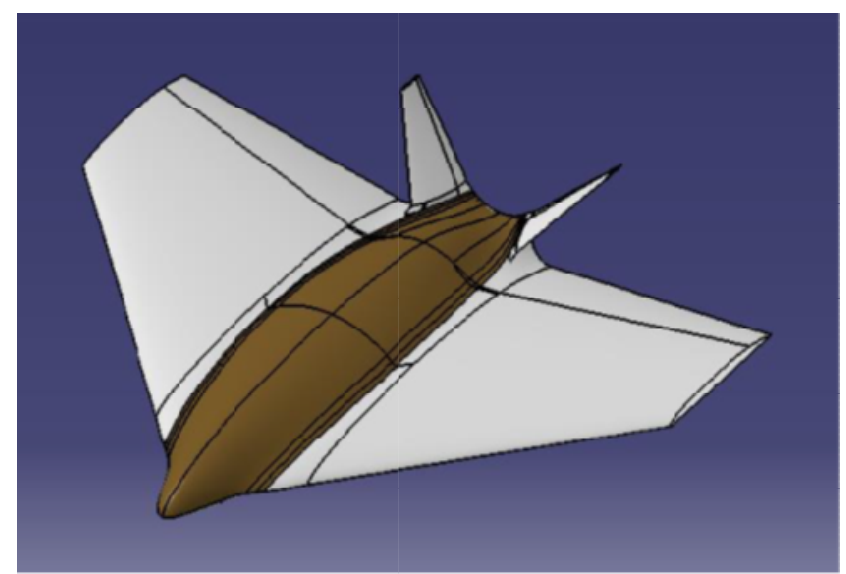

Fig 8: Elliptical Fuselage

Hence an elliptical fuselage (combination of sphere and cylinder) was created having the same dimensions as the cylinder and was analyzed for stress, and the results are as shown in fig10. 


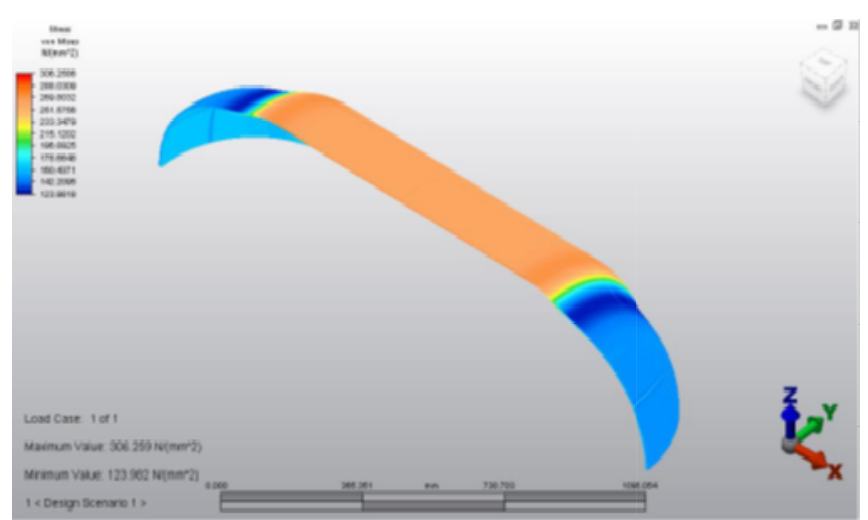

Fig 9: Cylindrical Shape Analysis Report

A load of $10 \mathrm{~N} / \mathrm{mm} 2$ was applied on both the bodies under consideration (cylinder and ellipse) having the same material, volume, area and weight.

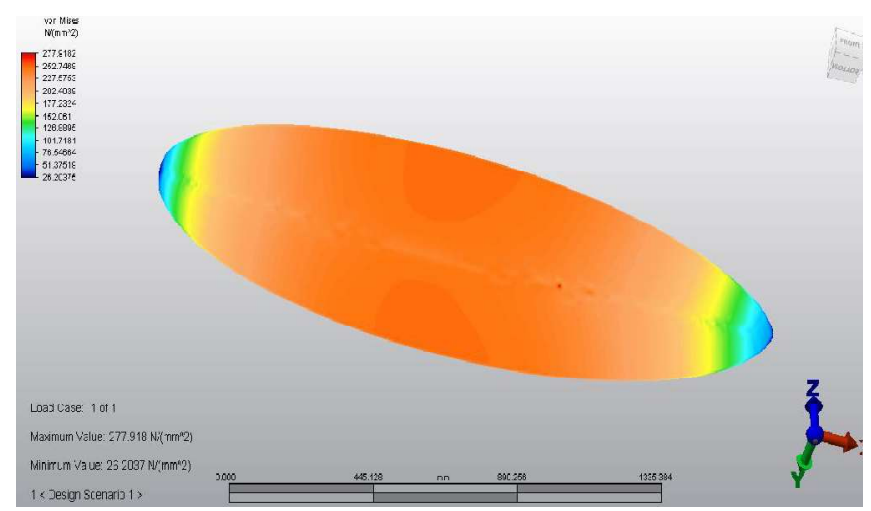

Fig 10: Elliptical Analysis Report

We found minimum stress value for elliptical Shape to be 26 $\mathrm{N} / \mathrm{mm} 2$ and for cylindrical shape the maximum stress value to be $277 \mathrm{~N} / \mathrm{mm} 2$.

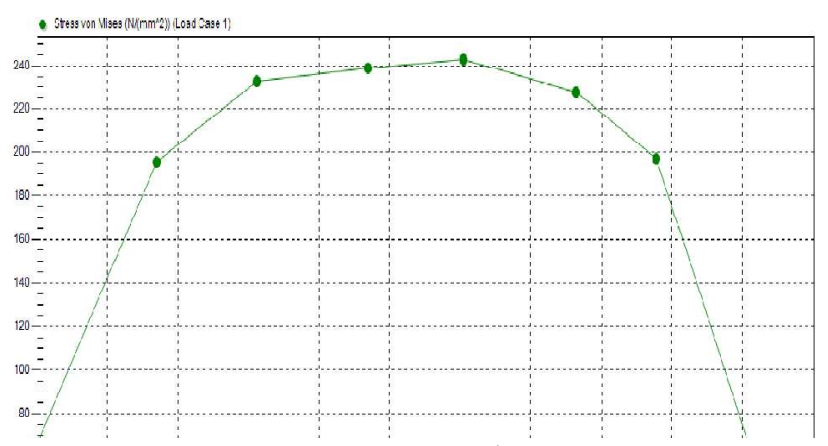

Fig 11: Stress value

\subsection{Effect of Shape}

A load of $10 \mathrm{~N} / \mathrm{mm} 2$ was applied on both the bodies under consideration (cylinder and ellipse) having the same material, volume, area and weight.

For the Elliptical design, $78 \%$ reduction in the minimum stress value and $10 \%$ reduction in the maximum stress value were noticed.

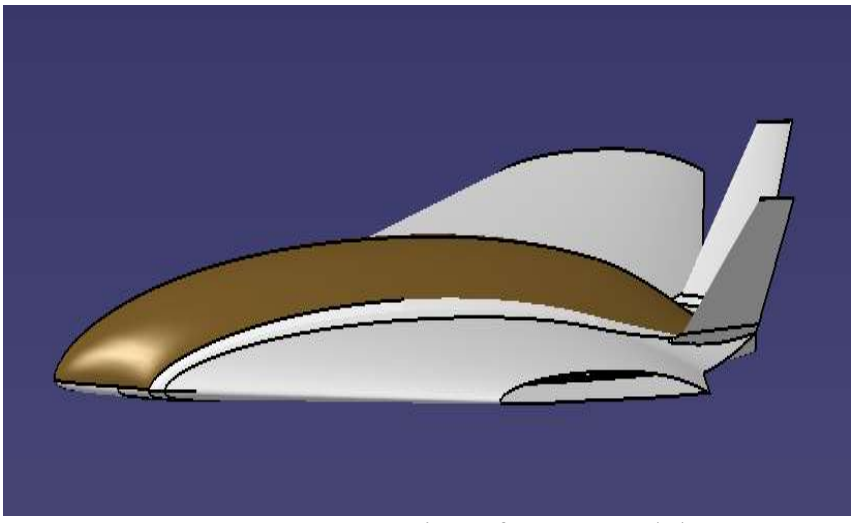

Fig 12: Cross section of CAD Model

\subsection{CFD Analysis}

In order to see the effect of Drag on the chosen shape, it is necessary to do a CFD analysis. Steps followed starts from Designing to Analyzing. Commercial Code ANSYs Fluent 17.0 was used to analyze.

An unstructured mesh with 1.2 million elements was chosen. Boundary conditions were taken as follows:

- Velocity Inlet: $35 \mathrm{~m} / \mathrm{s}$ inlet velocity

- Pressure Outlet: atmospheric pressure

Grid independent study was performed to select the mesh count. Convergence criteria of $1 \mathrm{e}-06$ were selected since it is a flow analysis without any heat generation. Pressure based solver was chosen and analysis was run.

Results obtained are as follows:

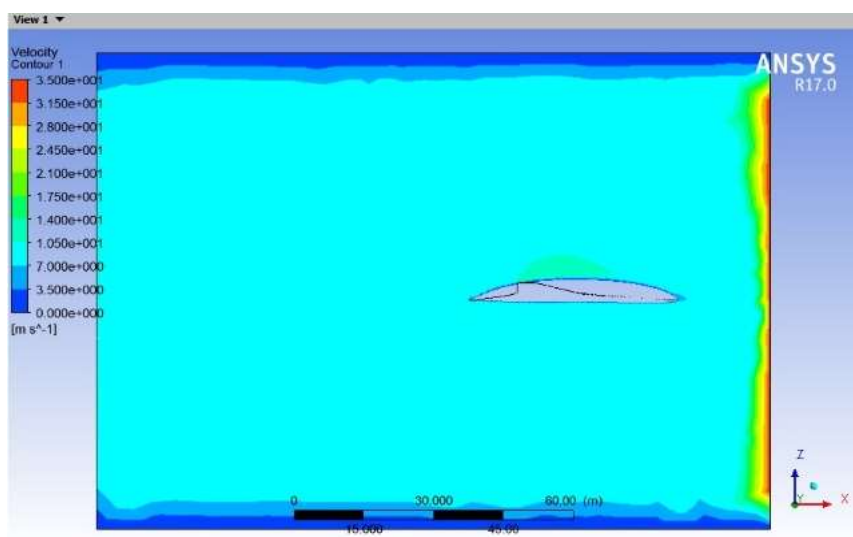

Fig 13: Velocity Contour over the cross section

Figure13 tells us the velocity distribution over the cross section of the aircraft. There is not much fluctuations in the flow at zero degrees.

Moving on to the pressure distribution over the cross section of the aircraft, 0 degree does not see a major change in pressure distribution over the surface which results in less flow separation. 


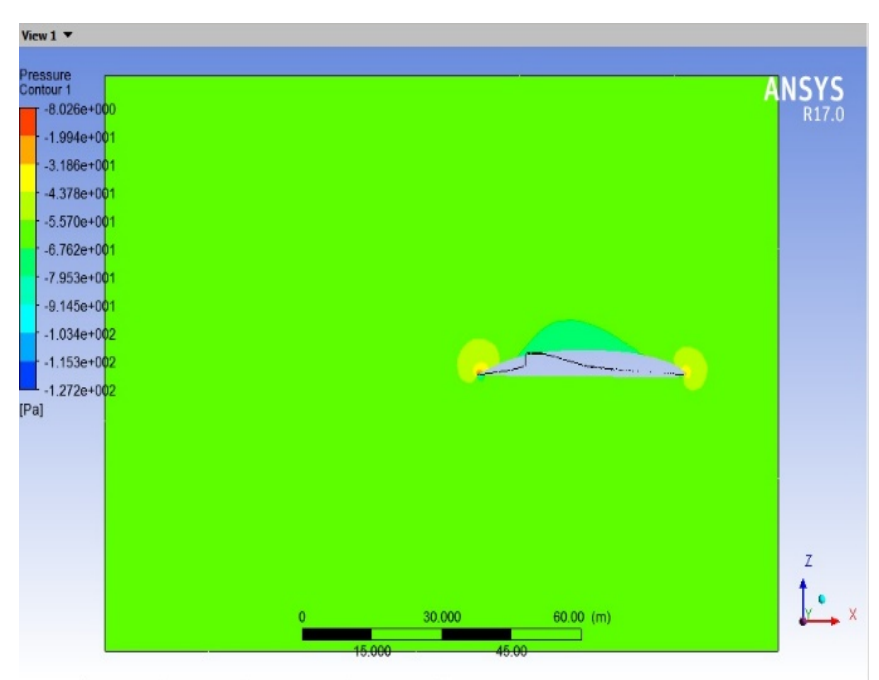

Fig 14: Pressure Contour over cross section

However, examining drag values at 0 and 5 degrees flow around the aircraft gives us interesting results. The body is kept stationary and flow is moving in the analysis.

The Aerodynamic Efficiency is then calculated on finding the $C_{L} / C_{D}$ values for 0 degree and 5 degree flow.

The value of $\mathrm{C}_{\mathrm{L}}$ comes to be 0.484 and $\mathrm{C}_{\mathrm{D}}$ comes up to be 0.007 . The Aerodynamic efficiency comes to approximately 65 . By reducing the drag value considerably which shows a good improvement in the design. However, there is not much increase in the $\mathrm{C}_{\mathrm{L}}$ value.

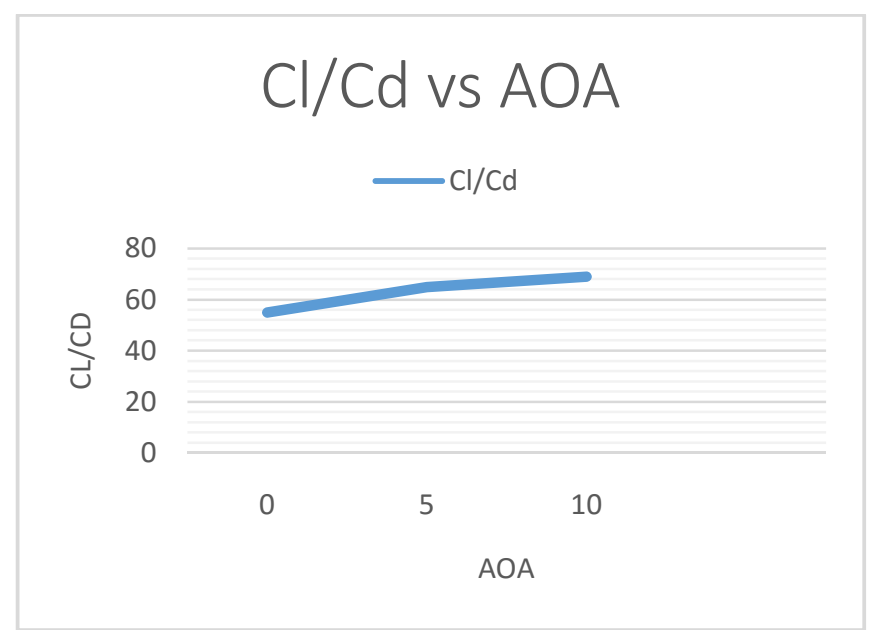

Fig: 15 Aerodynamic Efficiency

\section{CONCLUSION}

This paper studied the pressurization of a new fuselage design concept which integrates two shapes viz. a sphere and a cylinder. The resultant shape similar to an ellipse not only proved to provide better fuselage pressurization but also guaranteed a streamlined flow over its surface. The resultant effect is a drag minimizing fuselage which caters to better pressurization and minimal drag giving an aerodynamic efficiency of 65 at 5 degree angle of attack. Hoop Stress analysis shows the capacity to carry more load for elliptical shape. Reduction in minimum and maximum stress developing on the surface decreases by a significant amount of $88 \%$ and $10 \%$ respectively. Smooth aerodynamic shape results in less interference with the flow resulting in lesser drag and higher aerodynamic efficiency.

Future work is to be done to find the effect of this shape on more factors like having a wide range of velocities and angle of attacks.

\section{ACKNOWLEDGEMENT}

The authors would like to acknowledge the technical help and guidance of Prof. Dr. T.S. Krishnamurthy, Mr. Nikhil John and Mr. AravindSasikumar who have supported and helped us in our work.

\section{REFERENCES}

\section{Basic Format for Book}

[1]. Aircraft Structures for Engineering Students

By T.H.G. Megson

[2]. Strength of Materials - Stephen Timoshenko

[3]. A Textbook of Strength of Materials - RK Bansal

[4]. Strength of Materials by Basavarajaiah

[5]. Noise and Vibration Analysis by Brandt

[6]. Manufacturing Technology for Aerospace

Structural Materials by Campbell.

[7]. Advances in the Bonded Composite Repair of Metallic Aircraft Structure, Volume 1 by A.A. Baker, L.R.F. Rose, Rhys Jones

\section{Basic Format for Journals (When Available Online)}

[8]. A review of airship structural research and development by Lin Liao and Igor Pasternak "Progress in Aerospace Sciences, Volume 45, Issues 4-5, May-July 2009, Pages 83-96"

[9]. Jack R. Vinson "Sandwich Structures". Appl. Mech. Rev 54(3), 201-214 (May 01, 2001) (14 pages)doi:10.1115/1.3097295.

[10]. Leslie R. Koval "Effect of air flow, panel curvature, and internal pressurization on field-incidence transmission loss"

[11]. R. H. Liebeck. "Design of the Blended Wing Body Subsonic Transport", Journal of Aircraft, Vol. 41, No. 1 (2004), pp. 10-25.

[12]. Silvestro Barbarino ${ }^{1}$ Onur Bilgen ${ }^{2}$ Rafic M. Ajaj ${ }^{3}$, Michael I. Friswell ${ }^{4}$, and Daniel J. Inman "A Review of Morphing Aircraft”,Journal of Intelligent Material Systems and Structures June 2011 vol. 22 no. 9 823-877.

[13]. Guocai $\mathrm{Wu}^{1}$ and J. -M. Yang "The mechanical behavior of GLARE laminates for aircraft structures",JOM January 2005, Volume 57, Issue 1, pp 72-79,SpringerVerlag.

[14]. Sridhar Kota ${ }^{1}$, Joel A. Hetrick ${ }^{2}$, Russell Osborn ${ }^{3}$, Donald Paul ${ }^{4}$, Edmund Pendleton ${ }^{5}$, Peter Flick ${ }^{6}$, and Carl Tilmann "Design and application of compliant mechanisms for morphing aircraft structures",Industrial and Commercial Applications of Smart Structures Technologies, 24 (August 12, 2003); doi:10.1117/12.483869

[15]. J. $\quad{\text { Sobieszczanski-Sobieski }{ }^{1}, \quad \text { R. }}^{1}$ T. Haftka $^{2}$,"Multidisciplinary aerospace design optimization: 
survey of recent developments"August 1997, Volume 14, Issue 1, pp 1-23,Springer-Verlag.

[16] kroo,1.. "A n Interactive System for Aircraft Design and Optimization", AIAA Paper \#92-1190, Feb. 1992

[17]. B. Y. Kolesnikov", L. Herbeck", "Carbon Fiber Composite Airplane Fuselage: Concept and Analysis", Section II, Possible Ways of Russia-Europe Cooperation. April 2001, page 1-11.

[18]. S Buragohain $\mathrm{M}^{1}$.VelmuruganR ${ }^{2}$., 2011. "Study of filament wound grid-stiffened composite cylindrical structures, CompositeStructures", Vol. 93, No. 2, pp. 10311038

[19]. Marco, A. R ${ }^{1}$, Almeida, S. F. $\mathrm{M}^{2}$, "Design and Analysis of a Composite Fuselage", Brazilian Symposium on Aerospace Engg. \&Applications, September 2009, page 14-15.

[20]. Timothy Russell Gurney ${ }^{1}$ (1979), "Fatigue Of Welded Structures", 2nd Edition, CUP Archive. Howard Curtis, Antonio Filippone ${ }^{2}$, Michael Cook ${ }^{3}$, Lloyd R.Jenkinson ${ }^{4}$, Filippo De Florio $^{5}$ (2009), Aerospace Engineering Desk

Reference, Butterworth-Heinemann

\section{BIOGRAPHIES}

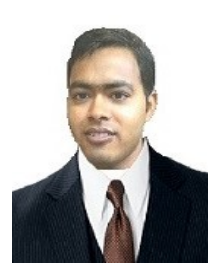

Mr. Manish Kumar is currently working as an Assistant Professor in Priyadarshini College of Engineering Nagpur. He completed Master of Engineering (M.E) in Space Engineering \& Rocketry from Birla Institute of Technology Mesra and B.E. in Aeronautical Engineering from Hindustan

University, Chennai.

E-id:manisrob@gmail.com

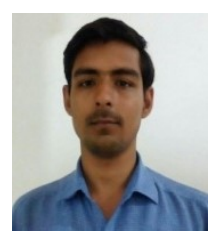

Mr. GeeteshWaghela is currently working as an Application Engineer, in ARK Info Solution. He completed Master of Technology (M.Tech) in Computational Fluid Dynamics from University of Petroleum and Energy Studies, Dehradoon and B.E. in Aeronautical Engineering from Hindustan University, Chennai.

E-id:geeteshwaghela1234@gmail.com

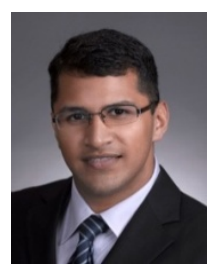

Mr. NakashNazeer is currently pursuing Master of Science (MSc.) in Aerospace Engineering (structures and materials) from Nanyang Technological University, Singapore. He completed B.E. in Aeronautical Engineering from Hindustan University, Chennai.

E-id: nakash1422@yahoo.com 